\title{
IMPLEMENTASI MOBILE LEARNING DENGAN MODEL ADVANCE ORGANIZER DALAM MENINGKATKAN KEMAMPUAN KOGNITIF KIMIA MAHASISWA
}

\author{
Salim Efendi ${ }^{1)}$, Ricard Fredrik Marpaung ${ }^{2}$, \\ ${ }^{1)}$ Fakultas Keguruan dan Ilmu Pendidikan, Universitas Efarina \\ ${ }^{2)}$ Fakultas Kesehatan, Universitas Efarina \\ salim.efendi@unefa.ac.id
}

DOI : 10.31604/ptk.v1i3.171-178

\begin{abstract}
The use of internet-based information technology on computers in the information network that is learned through cellular technology, cellular-based applications is easier to use the material provided by lecturers, the presence of mobile learning technology becomes a liaison between students and lecturers in learning, with mobile technology becoming a new alternative in providing learning content/items that are more innovative and dynamic. This study uses qualitative data relating to the questionnaire by looking at the feasibility of mobile learning media that contains relevant indicators on the National Education Standards Agency and quantitative data to determine the results of the effectiveness of mobile learning with advanced organizer models in improving chemical cognitive abilities. This is all study program pharmacy Efarina university students. Data was collection by objective tests for student learning outcomes. Data were analyzed using SPSS 17.0 with a significant level of 0.05 . The results of the study are in the form of mean validation to determine whether or not the media of mobile learning is feasible. The results obtained: (1) The composition of the material/media framework on mobile learning media is feasible and in accordance with the Curriculum (2) Mobile learning media developed for the pharmacy study program in the first semester class is feasible to use the results of standardization 3.58, standardization of language feasibility 3.66, standardization of presentation feasibility of 3.72, graphics standardization of 3.69 (3) is certainly the result that is significant improvement in cognitive abilities of students with the implementation of mobile learning with advance organizer models (Sig.1-tailed $<\alpha$ $(0.0285<0.05))$.
\end{abstract}

Keywords: Mobile Learning, Advance Organizer, Cognitive Abilities.

\begin{abstract}
Abstrak
Penggunaan teknologi informasi berbasis internet pada komputer dalam mengakses sumber belajar seiring waktu mulai beralih ke teknologi mobile, aplikasi berbasis mobile dipandang lebih mudah dalam mengakses materi pembelajaran yang disediakan oleh dosen, hadirnya teknologi mobile learning menjadi penghubung antara mahasiswa dan dosen dalam pembelajaran, dengan teknologi mobile menjadi alternatif baru dalam penyediaan konten/item pembelajaran yang lebih inovatif dan dinamis. Penelitian ini menggunakan data kualitatif yang dijelaskan melalui angket dengan lembar kelayakan media mobile learning yang berisi indikator-indikator penilaian yang merujuk pada Badan Standar Nasional Pendidikan (BSNP) dan data kuantitatif untuk mengetahui hasil
\end{abstract}


efektifitas mobile learning dengan model advance organizer dalam meningkatkan kemampuan kognitif kimia mahasiswa Populasi penelitian ini adalah seluruh mahasiswa program studi farmasi universitas Efarina. Pengumpulan data dilakukan dengan tes objektif untuk hasil belajar mahasiswa. Data dianalisis menggunakan SPSS 17.0 dengan taraf signifikan 0,05 . Hasil penilaian berupa rerata tentang validasi untuk menentukan layak atau tidaknya bahan media mobile learning. Hasil yang diperoleh: (1) Telah diperoleh susunan urutan materi/sub materi pada media mobile learning telah layak dan sesuai dengan Kurikulum (2) Media mobile learning yang dikembangkan untuk program studi farmasi kelas semester I telah layak untuk digunakan berdasarkan hasil standarisasi kelayakan isi sebesar 3.58, standarisasi kelayakan bahasa sebesar 3,66, standarisasi kelayakan penyajian sebesar 3,72, standarisasi kegrafikaan sebesar 3,69 (3) Terdapat hasil yang dignifikan peningkatan kemampuan kognitif mahasiswa dengan implementasi mobile learning dengan model advance organizer (Sig.1-tailed $<\alpha(0,0285<0,05)$ ).

Kata Kunci: mobile learning, advance organizer, Kemampuan Kognitif.

\section{PENDAHULUAN}

Ilmu kimia merupakan salah satu ilmu pengetahuan alam (IPA) yang memegang peranan penting serta pengaruh yang signifikan terhadap perkembangan dan kemajuan teknologi. Bidang studi ini memiliki peran penting dan banyak digunakan dalam kehidupan sehari-hari, seperti bahan makanan, minuman, pakaian bahkan industri. Melihat begitu pentingnya kimia dalam kehidupan manusia dan teknologi para siswa perlu dibekali penguatan kemampuan kimia agar menghasilkan Sumber Daya Manusia (SDM) yang kompeten, agar mampu mengikuti perkembangan ilmu dan teknologi yang saat ini menjadi prioritas pembangunan.

Pada pembelajaran kimia, tidak sedikit mahasiswa yang mengalami kesulitan belajar. Hal ini terlihat dari hasil wawancara yang dilakukan terhadap beberapa mahasiswa pada observasi awal yang dilakukan peneliti, mereka mengatakan bahwa mereka kurang bahkan tidak tertarik dengan pelajaran kimia, karena banyak konsepkonsep yang harus dihapalkan dan perhitungan-perhitungan yang sangat rumit dan dianggap sulit, penyajian materi yang tidak menarik dan cenderung membosankan bagi siswa. Di samping itu pembelajaran pada umumnya masih berlangsung secara konvensional dengan metode ceramah dan metode tanya jawab, dimana konsep-konsep transfer secara utuh oleh guru kepada siswa. Hal ini juga dikemukakan Sunyono (2005) ia mengatakan bahwa proses pembelajaran kimia selama ini cenderung kurang menarik, siswa merasa jenuh dan kurang memiliki minat pada pelajaran kimia, suasana kelas cenderung pasif dimana siswa yang bertanya pada guru sangat sedikit meskipun materi yang diajarkan belum dapat dipahami.

Menurut Georgiev, dkk (2004) mengemukakan Pembelajaran konvensional yang dilaksanakan di ruangan kelas guru bertanggung jawab atas materi pembelajaran yang disampaikan kepada siswa memiliki banyak kekurangan/ kelemahan seperti keterbatasan akses lokasi belajar dan ketersediaan ragam materi pembelajaran, pada umumnya pembelajaran konvensional yang dilaksanakan memiliki tiga komponen utama peserta didik, guru dan bahan belajar dimana semuanya harus 
terwakilkan secara fisik di tempat belajar ataupun ruangan belajar, selain itu pembelajaran konvensional umumnya tidak sesuai untuk gaya belajar dan pendidikan yang menerapkan ujian online, diskusi, kolaborasi, animasi, video, mendengarkan dan pencarian pengetahuan. Dari kelemahan dan keterbatasan pembelajaran konvensional, dewasa ini telah menghasilkan inovasi metode pendidikan dan pembelajaran baru, diantaranya berkembangnya media elektronik berbasis international networking (internet) di bidang pendidikan telah melahirkan sistem electronic-learning (e-learning) yang memberikan kemudahan pendidik melakukan aktivitas pembelajaran belajar kapan dan di lokasi mana saja yang berbeda, e-learning mengacu pada penggunaan teknologi dalam pembelajaran yang berbeda kegiatan dan untuk membantu orang untuk belajar dari jarak jauh. Konsep e-learning mencakup model yang berbeda seperti berbasis web belajar, ruang kelas virtual, pembelajaran berbantuan komputer dan komunikasi digital (Sarrab, dkk : 2013). Perkembangan pengguna perangkat smartphone di Indonesia berbanding lurus dengan perkembangan pengguna internet. Menurut analis kawakan Horace $H$. Dediu melalui blognya asymco.com, pengguna smartphone berbasis sistem operasi android di dunia pada tahun 2013 telah mencapai 1 miliar mengalahkan sistem operasi besutan Apple, iOS yang hanya mencapai 700 juta pengguna. Selain itu, disebutkan pula bahwa pengguna smartphone aktif di Indonesia pada 2013 mencapai 47 juta atau sekitar $14 \%$ dari total pengguna ponsel pintar di dunia. Angka ini menempatkan Indonesia pada posisi keenam dalam tangga jumlah populasi pengguna ponsel di dunia di bawah China, Amerika Serikat, India, Brazil dan Jepang (Heriyanto, 2014).

Penggunaan smartphone dan mobile device berbasis Android memiliki dampak positif dan negatif. Beberapa dampak posi-tif yang timbul adalah akses informasi dan komunikasi yang lebih cepat, mudah dan efisien. Selain itu, proses mengirim doku-men, promosi di internet dan sosial media semakin pesat. Dampak positif lainnya membantu memudahkan berbagai pekerja-an manusia dalam berbagai bidang. Ada-pun dampak negatif yang ditimbulkannya seperti banyak waktu yang terbuang, mi-salnya terlalu lama di sosial media, mela-yani chating via instant messaging dan main games hingga lupa waktu. Hal itu didu-kung oleh fakta di lapangan, yang menunjukkan bahwa penggunaan smartphone yang dimiliki oleh responden yang lebih banyak digunakan untuk aktivitas di sosial media dibandingkan dengan kegiatan pembelajaran. Data menunjukkan $90,3 \%$ peserta didik memiliki dan menggunakan aplikasi BBM, 93,5\% peserta didik menggunakan aplikasi Whatapps, 80,6\% memiliki akun Twitter, 77,4\% menggunakan akun Facebook (Surahman, 2015).

Perangkat mobile pada dasarnya memiliki tingkat fleksibilitas dan portabilitas yang sangat tinggi sehingga memungkinkan mahasiswa mengakses materi, bahan pembelajaran arahan dan informasi yang berkaitan dengan pembelajaran kapanpun dan dimanapun. Menurut Yuniati (2011), mobile learning mampu menjadikan mobilephone yang awalnya hanya digunakan untuk sms, telepon, chatting, dan internet menjadi alat belajar lengkap yang berisi materi pelajaran. Selain itu, peserta didik dapat menggunakan waktu belajarnya dengan lebih leluasa dan memiliki kesempatan lebih besar untuk 
PeTeKa (Jurnal Penelitian Tindakan Kelas dan Pengembangan Pembelajaran)

Vol 1 No 3 Tahun 2018 Hal 171-178

meningkatkan hasil belajarnya. Mobile learning juga dapat dijadikan sebagai salah satu alternatif untuk memecahkan permasalahan dalam bidang pendidikan terutama pada masalah pemerataan akses infomasi pendidikan, kualitas konten pembelajaran yang berupa materi dengan bentuk teks ataupun gambar disertai dengan contoh-contoh soal serta peningkatan kualitas pengajar atau guru agar lebih baik dalam membuat atau menyampaikan materi pembelajaran dan mengelola kegiatan belajar mengajar. Mobile learning memberikan harapan baru sebagai alternatif solusi atas sebagian besar permasalahan pendidikan, dengan fungsi yang dapat disesuikan dengan kebutuhan, baik sebagai suplemen (tambahan), komplemen (pelengkap), ataupun substitusi (pengganti) atas kegiatan pembelajaran di dalam kelas yang selama ini digunakan. Mobile learning juga dapat dikombinasikan dengan berbagai metode dan model pembelajaran yang digunakan oleh guru dalam kegiatan pembelajaran.

Dari permasalahan tersebut disadari bahwa pengaruh penggunaan mobile learning merupakan faktor eksternal yang penting dalam mengembangkan sekaligus meningkatkan hasil blajar kimia mahasiswa maka penulis tertarik untuk melakukan suatu penelitian dengan judul "Implementasi Mobile Learning Dengan Model Advance Organizer Dalam Meningkatkan Kemampuan Kognitif Kimia Mahasiswa"

\section{METODE}

Penelitian telah dilaksanakan secara bertahap di kota Pematangsiantar, Sumatera Utara pada bulan Agustud sampai Nopember 2018, Ke dalam interval waktu ini sudah termasuk: kegiatan survei pendahuluan, analisis materi pembelajaran, penyusunan proposal, penyusunan bahan ajar kimia larutan dengan media mobile learning, standarisasi bahan ajar, mempersiapkan GBPP, RPS, uji coba instrumen, pengumpulan data,observasi, analisis data, penulisan laporan akhir penelitian.

Sampel penelitian ini dipilih secara acak sederhana (simple random sampling), Sampel dianggap homogen dengan sampel yang digunakan 60 orang dalam dua kelas eksperimen yaitu: diperoleh satu kelas diberi pembelajaran dengan model Advance Organizer dengan menggunakan menggunakan media mobile learning hasil Pengembangan (E-1) dan kelas lainnya diberi pembelajaran dengan model Advance Organizer tanpa menggunakan menggunakan mobile learning Hasil Pengembangan (E-2). Pada pokok bahasan larutan asam basa.

Data penelitian yang diperoleh berupa data standarisasi media pembelajaran menggunakan mobile learning hasil pengembangan dan data hasil belajar. Untuk analisisnya dilakukan uji normalitas dengan menggunakan uji Kolmogorov-Smirnov Test Mengunakan program SPSS 17.0 For Windows dengan Kriteria pengujian adalah Sigh $_{\mathrm{h}}>\alpha(0,05)$ maka data terdistribusi normal. Untuk mengetahui apakah data berasal dari populasi yang bervarians sama (homogen) digunakan uji Levene Statistic pada taraf signifikansi 0,05. Dengan menggunakan program SPSS 17.0 For Windows.

Untuk pengujian hipotesis digunakan uji satu pihak menggunakan data sampel independen $\mathrm{T}$ - test.untuk hipotesis menggunakan program SPSS 17. For Windows. 
HASIL DAN PEMBAHASAN

\section{Standarisasi Media Mobile Learning}

Media pembelajaran mobile

learning terlebih dahulu distandarisasi menggunakan penilai ahli (Dosen kimia dan ahli komputer) sehingga dapat dipergunakan sebagai media pembelajaran yang standar dalam proses belajar mengajar dalam pengajaran. Berdasarkan hasil uji coba Media pembelajaran mobile learning larutan kepada dosen dan ahli komputer, umumnya responden mengisi kolom (3) dan (4) yang bearti secara umum responden setuju dengan Media pembelajaran mobile learning standar yang diajukan penulis. Berikut ini merupakan rata-rata yang diperoleh dari uji kelayakan Media pembelajaran mobile learning standar yaitu: (1) Hasil rata-rata yang diperoleh untuk analisis standar kelayakan isi adalah sebesar 3,58 (2) Hasil rata-rata yang diperoleh untuk untuk analisis standar kelayakan bahasa adalah sebesar 3,66 (3) Hasil rata-rata untuk analisis standar kelayakan penyajian adalah sebesar 3,72 (4) Hasil rata-rata yang diperoleh untuk analisis standar kelayakan kegrafikaan adalah sebesar 3,69 dan persentase aspek kelayakan isi, Bahasa, Penyajian dan kegrafikaan rata-rata diperoleh pada kriteria sangat baik yaitu pada kisaran $80 \%$ - $100 \%$ yang berarti bahwa isi Media pembelajaran mobile learning yang diajukan penulis sudah standard dan valid.

Rudzitis (2003) mengemukakan kualitas dari suatu bahan ajar teks adalah sesuatu yang sangat penting pada pembelajaran sains. Hasil rata-rata yang diperoleh untuk masing-masing analisis standar kelayakan yang diajukan kepada dosen dan guru kimia memperlihatkan kesepakatan berada pada kisaran 3,34 4,00 yang berarti bahwa dosen dan ahli komputer setuju dengan media pembelajaran mobile learning standar yang diajukan dan tidak perlu dilakukan revisi kembali. Selanjutnya media pembelajaran mobile learning standar yang telah divalidasi kepada dosen dan ahli komputer selanjutnya dapat dipergunakan dalam pembelajaran.

Untuk mengetahui seberapa besar peningkatan hasil belajar siswa yang diajarkan dengan media pembelajaran mobile learning maka dilakukan penelitian eksperimen tempat peneliti mengajar. Berdasarkan hasil analisis data angket standar kelayakan maka diperoleh media pembelajaran mobile learning yang layak dan sesuai dengan kurikulum.

\section{Deskripsi Data Penelitian Implementasi Media Pembelajaran Mobile Learning}

\section{a) Penilaian kognitif mahasiswa}

Kemampuan kognitif mahasiswa dalam pembelajaran dari pretest, posttest untuk kedua kelas. Berikut hasil dari kemampuan kognitif mahasiswa.

Tabel 1: Kemampuan Kognitif Mahasiswa

\begin{tabular}{ccccc}
\hline Nilai & \multicolumn{3}{c}{ Eksperimen I Eksperimen II } \\
Pretest & Postest & Pretest & Postest \\
\hline Rata-rata & 33,25 & 75,50 & 33,50 & 72,25 \\
Std deviasi & 11,32 & 10,23 & 14,10 & 8,29 \\
$\begin{array}{c}\text { Nilai } \\
\text { maksimum } \\
\text { Nilai } \\
\text { minimum }\end{array}$ & 55 & 90 & 60 & 85 \\
\hline
\end{tabular}


PeTeKa (Jurnal Penelitian Tindakan Kelas dan Pengembangan Pembelajaran)

Vol 1 No 3 Tahun 2018 Hal 171-178

\section{b) Uji Persyaratan Data}

Sebelum dilakukan pengujian hipotesis maka terlebih dahulu dilakukan pengujian persyaratan data sebagai syarat awal untuk pengujian statistik lebih lanjut. Uji yang digunakan adalah uji Kolmogorov-Smirnov pada taraf signifikansi 0,05 . Kemudian uji homogenitas data menggunakan $u j i$ Levene Statistic pada taraf signifikansi 0,05 . Pengujian dilakukan dengan menggunakan program SPSS 17. For Windows.

Table 2: Hasil Uji Normalitas Data

\begin{tabular}{lcccc}
\hline \multicolumn{1}{c}{ Kelas } & Data & Sig & $\boldsymbol{\alpha}$ & Ket \\
\hline Eks I & Pretes & 0,064 & 0,05 & Norm \\
Eks II & & 0,542 & 0,05 & Norm \\
Eks I & & 0,220 & 0,05 & Norm \\
Eks II & Postest & 0,246 & 0,05 & Norm \\
Eks I & & 0,477 & 0,05 & Norm \\
Eks II & Gain & 0,781 & 0,05 & Norm \\
\hline
\end{tabular}

Table 3: Test of Homogeneity of Variances

\begin{tabular}{|c|c|c|c|c|}
\hline \multicolumn{5}{|c|}{ Data Kedua Kelas Eksperimen } \\
\hline $\begin{array}{c}\text { Levene } \\
\text { Statistic } \\
\end{array}$ & df1 & df2 & Sig. & Ket \\
\hline & 1 & 58 & 0.186 & \\
\hline Post & 1 & 58 & 0,241 & gen \\
\hline Gain & 1 & 58 & 0.672 & Homogen \\
\hline
\end{tabular}

\section{c) Keefektifan Implementasi Media Mobile Learning pada Pembelajaran Kimia.}

Berdasarkan hasil belajar siswa pada subpokok bahasan asam basa yang diajarkan dengan menggunakan media pembelajaran dengan media mobile learning berdasarkan kurikulum diperoleh sebesar $6,34 \%$.

\section{Optimalisasi Peningkatan Kemampuan Kognitif Mahasiswa Melalui Implementasi Media Pembelajaran Mobile Learning pada model Advance Organizer.}

Secara keseluruhan mahasiswa yang belajar menggunakan Advance Organizer dengan menggunakan media mobile learning hasil Pengembangan hasil pengembangan mendapatkan gain hasil belajar yang tinggi (0,680 dengan persen peningkatan hasil belajar sebesar 68,00\%) dibandingkan dengan mahasiswa yang belajar tanpa Advance Organizer dengan menggunakan menggunakan media mobile learning hasil Pengembangan hasil pengembangan (0,57 dengan persen peningkatan hasil belajar sebesar 57,00\%) pada pokok bahasan larutan asam basa kelas semester ganjil T.A 2018/2019.

Berdasarkan hasil pengujian hipotesis, melalui pengujian data menggunakan SPSS 17.0 For Windows diketahui bahwa media mobile learning hasil pengembangan pada model Advance Organizer berpengaruh secara signifikan terhadap hasil kognitif mahasiswa. Dimana hasil belajar kimia mahasiswa yang diajar dengan media mobile learning hasil pengembangan lebih tinggi dari pada hasil belajar kimia siswa yang diajar tanpa media mobile learning hasil pengembangan dengan harga Sig. (1-tailed) $=0,0285$ (tingkat kesalahan 0,0285 \%) lebih kecil dari 0,050 (tingkat kesalahan 5\%, tingkat kepercayaan $95 \%$ ).

Harga ini menunjukkan bahwa untuk tingkat kepercayaan $95 \%$ bahwa media mobile learning hasil pengembangan pada model Advance Organizer berpengaruh secara signifikan terhadap hasil belajar siswa dengan tingkat signifikansi diyakini 99,97\%. Maka diperoleh kesimpulan bahwa hipotesis diterima. Artinya Hasil 
Salim Efendi, dkk. Implementasi Mobile Learning Dengan Model Advance ...

kognitif mahasiswa Program Studi Farmasi semester I yang diajarkan dengan implementasi bahan media mobile learning yang telah dikembangkan berdasarkan kurikulum. model Advance Organizer lebih tinggi dibandingkan dengan hasil belajar siswa yang diajarkan dengan Advance Organizer tanpa implementasi media mobile learning yang telah dikembangkan berdasarkan kurikulum.

Dengan demikian terlihat bahwa penggunaan media media mobile learning yang telah dikembangkan efektif terhadap peningkatan kemampuan kognitif mahasiswa hal ini dijelaskan lebih lanjut menurut Majid (2012: 4-5), terdapat tiga fungsi utama mobile learning dalam proses pembelajaran, yaitu sebagai suplemen (tambahan), sebagai pelengkap (komplemen), dan sebagai substitusi (pengganti). Mobile learning dapat berfungsi sebagai suplemen apabila peserta didik mempunyai kebebasan dalam memanfaatkan atau tidak. Mobile learning dapat berfungsi sebagai komplemen apabila dimanfaatkan sebagai program pelengkap materi pembelajaran yang diajarkan kepada peserta didik di kelas.

Dalam hal ini, mobile learning berperan sebagai penguatan (reinforcement) atau pengulangan (remedial) bagi peserta didik yang tidak dapat memenuhi standar. Adapun mobile learning yang berfungsi sebagai substitusi apabila model kegiatan pembelajaran menggunakan mobile learning secara penuh. Hal ini bertujuan agar peserta didik dapat menggunakan waktu mereka secara fleksibel dalam mengelola kegiatan perkuliahannya sesuai dengan waktu dan aktifitas mereka sehari-hari.

\section{SIMPULAN}

Telah diperoleh bahan media mobile learning kimia larutan untuk program studi farmasi semester I yang sesuai kurikulum yang terdiri dari 4 pokok bahasan yaitu Larutan Asam Basa, Stoikiometri Larutan, Hidrolisis Garam, Larutan Penyangga. Media mobile learning yang dikembangkan program studi farmasi semester I telah layak dan sesuai dengan kurikulum. Hasil rata-rata yang diperoleh dari angket yang diberikan kepada dosen dan guru untuk analisis standar kelayakan isi sebesar 3.58, analisis standar kelayakan bahasa sebesar 3,66, analisis standar kelayakan penyajian sebesar 3,72, analisis standar kelayakan kegrafikaan sebesar 3,69 yang menunjukkan bahwa dosen dan guru kimia setuju dengan bahan ajar kimia larutan standar yang diajukan telah layak dan sesuai dengan kurikulum. Terdapat peningkatan yang dignifikan hasil peningkatan kemampuan kognitif mahasiswa yang diberi pembelajaran dengan implementasi dengan media mobile learning dikembangkan dalam penelitian ini.

\section{DAFTAR PUSTAKA}

Georgiev, E. G., \& Smrikarov, A. 2004. M-Learning - a New Stage of ELearning, International Conference on Computer Systems and Technologies CompSysTech' 2004.

Heriyanto, Trisno. 2014. Indonesia Masuk 5 Besar Negara Pengguna Smartphone. Diakses dari http://inet.detik.com/read /2014/02/03/171002/ 2485920/ 317/indonesia-masuk-5-besarnegara-pengguna-smartphone pada 28 April 2015. 
PeTeKa (Jurnal Penelitian Tindakan Kelas dan Pengembangan Pembelajaran)

Vol 1 No 3 Tahun 2018 Hal 171-178

Sarrab, M., Al-Shihi, H., \& Rehman, O. 2013. Exploring Major Challenges and Benefits of $\mathrm{M}$ learning Adoption. British Journal of Applied Science \& Technology 3(4).

Surahman, E. 2015. Laporan observasi kepemilikan dan pemanfaatan perangkat telekomunikasi siswa SMAN 1 Depok Sleman Yogyakarta. Yogyakarta.

Yuniati, L. 2011. Pengembangan Media Pembelajaran Mobile Learning Efek Doppler Sebagai Alat Bantu Dalam Pembelajaran Fisika Yang Menyenangkan. JP2F 2(2). 